\title{
Graphitic Carbon Nitride-Graphene Hybrid Nanostructure as a Catalyst Support for Polymer Electrolyte Membrane Fuel Cells
}

\author{
Noramalina Mansor ${ }^{\mathrm{a}}$, Jingjing Jia ${ }^{\mathrm{b}}$, Thomas S. Miller ${ }^{\mathrm{c}}$, Theo Suter ${ }^{\mathrm{c}}$, Ana Belen Jorge ${ }^{\mathrm{d}}$, \\ Chris Gibbs ${ }^{\mathrm{e}}$, Paul Shearing ${ }^{\mathrm{a}}$, Paul F. McMillan ${ }^{\mathrm{c}}$, Cecilia Mattevi ${ }^{\mathrm{f}}$, Milo Shaffer ${ }^{\mathrm{b}}$, \\ Daniel J. L. Brett ${ }^{\mathrm{a}}$ \\ ${ }^{a}$ Electrochemical Innovation Lab, Department of Chemical Engineering, University \\ College London, London WC1E 7JE \\ ${ }^{\mathrm{b}}$ Department of Chemistry, Imperial College London, London SW7 2AZ \\ ${ }^{c}$ Department of Chemistry, University College London, London WC1H 0AJ \\ ${ }^{\mathrm{d}}$ Materials Research Institute, School of Engineering and Materials Science, Queen Mary \\ University, London E1 4NS \\ ${ }^{e}$ UCL Business, The Network Building, 97 Totenham Court Road, London W1T 4TP \\ ${ }^{\mathrm{f}}$ Department of Materials, Imperial College London, London SW7 2AZ
}

Graphitic carbon nitrides form a class of semiconducting graphenelike polymeric materials with visible light absorption and photocatalytic properties. In addition to high nitrogen content and tunable structure, it was shown that graphitic carbon nitride based on polytrazine imide (PTI) sheets exhibit excellent anti-corrosion ability in ex-situ fuel cell environments. However, in bulk form, their low surface area and poor conductivity limits their applications in fuel cells. In this work, PTI was exfoliated to form an ink made from single to few-layer nanosheets. The ink was then processed to produce 3D networks of carbon nitride nanosheets/reduced graphene oxide (PTI-rGO) hybrid aerogel with large interconnecting pores for fast mass transport of reactants and high surface area. The material was decorated with platinum nanoparticles, and then investigated for its electrochemical properties and applications as a catalyst support for polymer electrolyte membrane (PEM) fuel cells. Initial results show that the cathode catalytic activity of $\mathrm{Pt} / \mathrm{rGO}$-PTI hybrid is significantly improved in comparison to $\mathrm{Pt} / \mathrm{PTI}$ or $\mathrm{Pt} / \mathrm{rGO}$. In addition, the insitu fuel cell performance of Pt/PTI as anode catalyst is comparable to commercial $\mathrm{Pt} / \mathrm{C}$ especially at low densities, making it attractive as an alternative, durable anode catalyst support material to conventional carbon black.

\section{Introduction}

Environmentally friendly energy conversion devices such as polymer electrolyte membrane (PEM) fuel cells play an important role in mitigating the ever-increasing energy consumption and climate change threats. Many advances have been made in the last few decades to improve the efficiency and performance of PEM fuel cells, but the electrodes 
still depend on rare and expensive precious metal catalysts, such as platinum. It is estimated that the electrodes contribute to about $42 \%$ of the total system costs (1). PEM fuel cell catalysts typically composed of active metal nanoparticles uniformly dispersed on high surface area supports, such as carbon black. This system maximises the electrochemical surface area of the catalyst, thus, minimizing the amount of active metal on the electrodes. Therefore, the support materials play an important role in the size distribution and stability of the metal nanoparticles on the electrode. In general, catalyst support requirements are: 1) high specific surface area, 2) high electronic conductivity, 3) high electrochemical stability under fuel cell operating conditions, 4) have a porous network to allow effective mass transport of reactants, and 5) low cost and environmentally friendly synthesis and processing.

The most widely used support material is carbon black, such as Vulcan XC-72R, due to its high surface area, low cost, minimal environmental impact and high electronic conductivity. However, it is known to be unstable at high potentials, especially in acidic environments such as found inPEM fuel cell, leading to carbon corrosion $(2,3)$. As a result, metal particles agglomerate into larger particles and detach from the support through various mechanisms such as Ostwald ripening, crystal migration and particle dissolution, leading to a loss in electrochemical surface area (ECSA) and catalytic activity $(4,5)$. Consequently, a wide range of alternative carbon-based materials has been investigated, such as graphitized carbon, carbon nanotubes, aerogels and more recently, graphene $(6,7)$. An emerging trend is to dope the carbon support materials with heteroatoms such as sulphur, phosphorous and boron (8-16), which may enhance the metal - particle interactions, and hence improve stability. Several studies have also shown that the presence of nitrogen in carbon improves both durability and catalytic activity (17-21). In addition, it was demonstrated that there is a strong "tethering" interaction between Pt nanoparticles and nitrogen atoms, and the N-dopant alters the catalyst electronic structure, leading to an increase in catalytic activity (22-25). However, such doping strategies can only introduce limited amount of nitrogen in the material (22).

There has also been a growing number of studies on the use of graphitic or polymeric carbon nitride materials $(\mathrm{gCNH})$, that contain a high concentration of nitrogen atoms ordered on lattice sites, as alternative catalyst supports (26-28). gCNH thus provides a new class of semiconducting graphene-like polymeric materials that are readily synthesized by thermal condensation of nitrogen-rich molecules such as dicyandiamide, melamine and urea (29). The structures are based on either linked heptazine $\left(\mathrm{C}_{6} \mathrm{~N}_{7}\right)$ units forming the polyheptazine structures (Figure 1a), or s-triazine rings $\left(\mathrm{C}_{3} \mathrm{~N}_{3}\right)$ linked via $\mathrm{N}$ atoms or $-\mathrm{NH}$ units to form the polytriazine imide (PTI) structures (Figure 1b) (30-32). The presence of $\mathrm{N}-\mathrm{H}$ functional groups and $\mathrm{N}$ lone pairs provide abundant Lewis acid and base sites that are potential anchoring positions for Pt as well as adsorption sites for poisoning intermediates (33). These materials are being developed for their catalytic and photocatalytic activity (32, 34-36). In addition, their excellent mechanical, chemical and thermal resistances make them a material of choice for PEM fuel cell electrode materials $(32,37,38)$. 

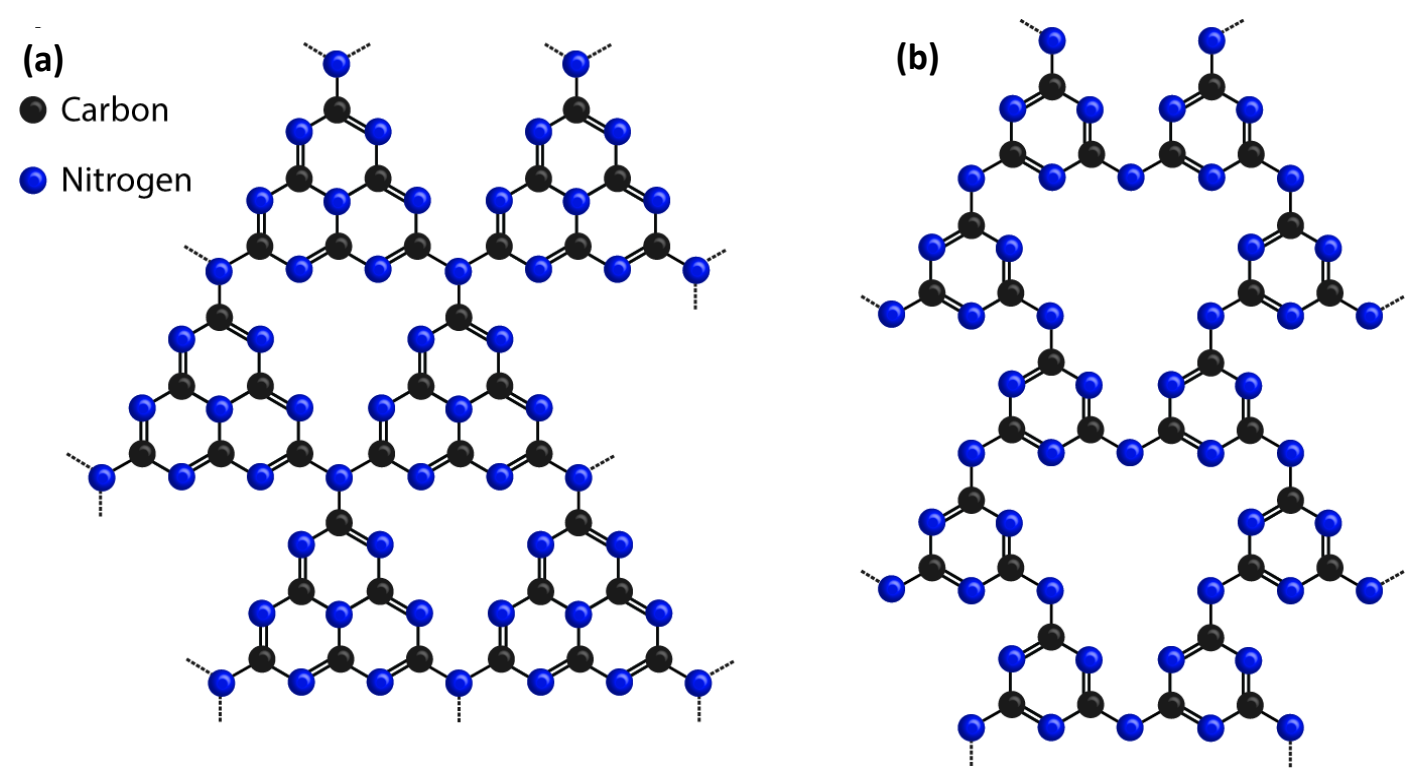

Figure 1. Structure motifs found among layers in graphitic carbon nitirides. (a) heptazine based graphitic carbon nitride (b) triazine based graphitic carbon nitride (PTI).

A first study on the use of gCNH as a catalyst support was reported by Kim et al. who showed that gCNH supported PtRu exhibited excellent performance in a direct methanol fuel cell (DMFC) with up to $83 \%$ higher power density compared to commercial $\mathrm{PtRu}$ /carbon (28). Another study by Mansor et al. showed that both polyheptazine and PTI based gCNH materials are more electrochemically stable compared to carbon black during an ex-situ accelerated corrosion test (26). In addition, it was found that Pt supported on PTI exhibits superior intrinsic methanol oxidation activity and excellent durability following a potential cycling test compared to commercial Pt on carbon black (26). However, gCNH in bulk form has low surface area and poor conductivity, which limits their practical applications in fuel cells. However, incorporating a conductive material to form a nanocomposite substrate increases the number of electrons accumulated on the gCNH surface, thereby facilitating the catalytic activity (39). Consequently, many studies have since focused on hybridizing $\mathrm{gCNH}$ with various carbon materials to use as metal-free catalysts and catalyst support for fuel cells $(40,41)$.

In recent years, graphene has attracted a lot of attention due to its promising chemical and physical properties and it has been studied as both catalyst and catalyst support due to its high surface area and conductivity (42-44). A Density Functional Theory (DFT) modeling on graphene-gCNH composite has demonstrated that there is a strong charge transfer from graphene to gCNH, that improves the electronic conductivity of gCNH (45). As a result, graphene is a preferred choice of conducting substrate for gCNHs, not least because of their complementary structure. Several studies have shown that metal-free gCNH-graphene composites exhibit excellent oxygen reduction reaction (ORR) catalytic activity, especially in alkaline electrolytes $(40,46,47)$. gCNH-graphene related composites have also been studied as catalyst supports; it was reported that Pd and PtRu supported on polyheptazine based $\mathrm{gCNH}$ and reduced graphene oxide (rGO) composites exhibit high catalytic activity for alcohol oxidation, as well as enhanced durability and alcohol tolerance $(48,49)$. 
One strategy reported by Huang et al. involves the assembly of 3D porous graphene$\mathrm{gCNH}$ hybrids from rGO and 'exfoliated' $\mathrm{gCNH}$, as a catalyst support for Pt. In addition to high electrical conductivity and large surface area, their aerogel hybrids provide a hierarchical pore network conducive for fast transport of reactants. It was shown to exhibit superior methanol oxidation activity, and high $\mathrm{CO}$ tolerance and stability, compared with $\mathrm{Pt} / \mathrm{C}$ and $\mathrm{Pt} / g r a p h e n e ~(50)$. A similar strategy has been employed by $\mathrm{Hu}$ et al. with similar findings, i.e. superior methanol oxidation activity and durability (44).

In this work, we assembled gCNH-graphene 3D hybrid materials using the highly crystalline and layered PTI based carbon nitride instead of the amorphous polymeric $\mathrm{gCNH}$. An exfoliation route was first established to produce PTI ink containing single to few-layer nanosheets. The ink was then processed to produce carbon nitride nanosheets/reduced graphene oxide (PTI-rGO) hybrid aerogel with large interconnecting pores for fast mass transport of reactants and high surface area. The material was decorated with nanocrystalline platinum that also acted as spacers to prevent the restacking of the nanosheets. We report results of the electrochemical properties of these nanocomposites and their potential applications as catalyst supports for PEM fuel cells.

\section{Experimental}

Synthesis of PTI based carbon nitride

Crystalline poly(triazine)imide $\left(\mathrm{PTI} / \mathrm{Li}^{+} \mathrm{Br}^{-}\right)$was synthesized from DCDA in molten eutectic $\mathrm{LiCl} / \mathrm{KBr}(45: 55 \mathrm{wt} \%)$ mixtures heated at $400{ }^{\circ} \mathrm{C}$ under $\mathrm{N}_{2}(\mathrm{~g})$ for $6 \mathrm{~h}$ and then sealed under vacuum and heated to $600{ }^{\circ} \mathrm{C}$ for $12 \mathrm{~h}$.

$\underline{\text { Synthesis of graphene oxide (GO) and exfoliation of PTI/Li }{ }^{+} \mathrm{Br}^{-}}$

Graphene oxide was synthesized from natural graphite flakes (Asbury Graphite Mills) following the modified Hummers' method (51). Few layer $\mathrm{PTI} / \mathrm{Li}^{+} \mathrm{Br}^{-}$nanosheets were fabricated by a one-step probe sonication process in aqueous solution, where specifically 50 $\mathrm{mg}$ of $\mathrm{PTI} / \mathrm{Li}^{+} \mathrm{Br}^{-}$powders and $20 \mathrm{ml}$ water were added into a $30 \mathrm{~mL}$ glass vial, followed by a 6-hour probe sonication process at $300 \mathrm{~W}$ intensity in an ice-bath, maintain at 0 degree during the whole sonication process, and then the dispersion was centrifuged at $5000 \mathrm{~g}$ for $30 \mathrm{~min}$ to remove the aggregated fragments. The resultant homogeneous light-yellow $\mathrm{PTI} / \mathrm{Li}^{+} \mathrm{Br}^{-}$nanosheet dispersion with a concentration of $\sim 0.5 \mathrm{mg} \mathrm{ml}^{-1}$ was obtained.

\section{Assembly of 3D PTI-rGO aerogel}

The PTI-GO hybrid hydrogel with different feeding ratios of PTI and GO were synthesized by mixing GO suspension and exfoliated PTI dispersion under the bath sonication for $30 \mathrm{~min}$. The mixture was further homogenized at $60{ }^{\circ} \mathrm{C}$ for 24 hours and venting the air under vacuum for 10 minutes before casting. The aqueous mixture was subsequently cast using a homemade round PTFE molds (Figure 2), and further frozen from room temperature to $-150{ }^{\circ} \mathrm{C}$ at a rate of $5{ }^{\circ} \mathrm{C} / \mathrm{min}$. Then the frozen sample was subjected into a $-45{ }^{\circ} \mathrm{C}$ and 1 mbar vacuum for sublimation of water in a freeze dryer (Freezone 4.5, Labconco Corporation). The as-prepared 3D hybrid hydrogel was further 
thermally reduced at $350{ }^{\circ} \mathrm{C}$ in $10 \% \mathrm{H}_{2} / 90 \%$ Ar atmosphere inside a tubular oven under vacuum. In this study, two ratios of PTI and $\mathrm{rGO}$ were investigated: 3.5:6 ( $\left.\mathrm{PTI}_{3}-\mathrm{rGO}_{6.5}\right)$ and 1:1 $\left(\mathrm{PTI}_{1}-\mathrm{rGO}_{1},\right)$. For comparison, pure $\mathrm{rGO}$ aerogel was also prepared.

PTI/rGO monolith

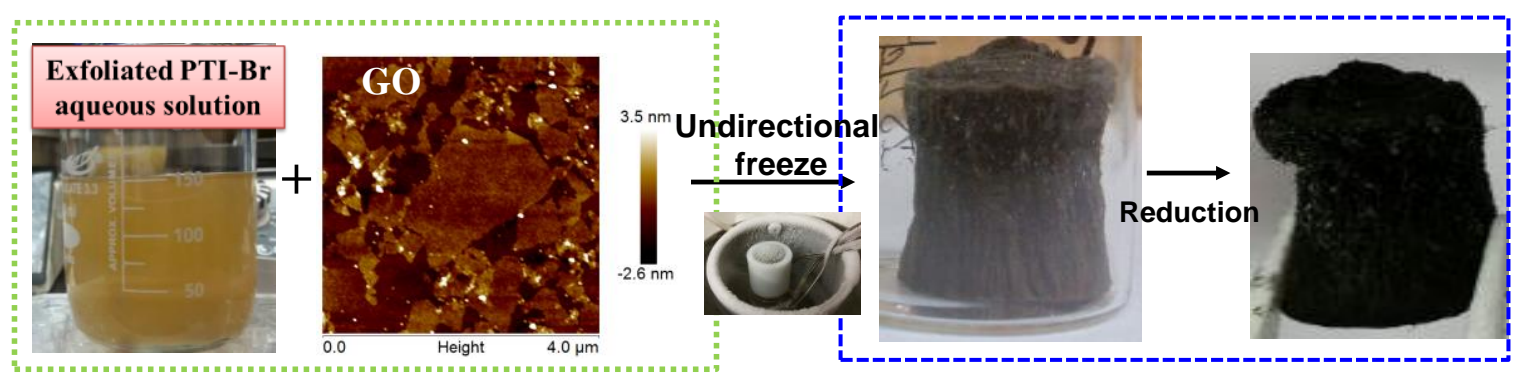

Figure 2. Schematic illustration of the preparation process of 3D PTI-rGO monolith

\section{$\underline{\text { Pt deposition }}$}

Pt was deposited on graphitic carbon nitride via the ethylene glycol reduction method. In general, PTI-rGO aerogel was dispersed in ethylene glycol (Fisher Scientific) and $\mathrm{H}_{2} \mathrm{PtCl}_{6}$ (39.15\% Pt, Sigma Aldrich) was added to the suspension. The mixture was heated for 12 hours at $160^{\circ} \mathrm{C}$. The solid product was collected via vacuum filtration and dried in an oven overnight at $60^{\circ} \mathrm{C}$. The Pt loading was fixed at $20 \mathrm{wt} \%$.

\section{Physical Characterizations}

Atomic force microscopy (AFM) was performed on samples drop-casted onto cleaned $\left(\mathrm{H}_{2} \mathrm{SO}_{4} / \mathrm{H}_{2} \mathrm{O}_{2}\right)$ silicon wafers, dried under vacuum for 48 hours. AFM micrographs were taken in tapping mode on a Digital Instruments Multimode VIII AFM with Nanoscope IV Digital Instruments AFM controller (Veeco) using Nanosensor tapping mode probes (Windsor Scientific). Scanning electron microscopy (SEM) images and energy dispersive X-ray (EDX) spectra were taken using a Leo Gemini 1525 FEGSEM at an accelerating voltage of $5 \mathrm{keV}$ for SEM, and $20 \mathrm{keV}$ for EDX, respectively. The transmission electron microscope (TEM) images were taken using a JEOL JEM2010 instrument operating at 200 $\mathrm{kV}$.

\section{Electrochemical characterisation}

Electrochemical measurements were carried out in a conventional three-electrode cell connected to a Gamry Interface 1000E potentiostat. The electrode ink was prepared by ultrasonicating the measured amount of catalyst material in 2-propanol solution (SigmaAldrich) and Nafion for 30 minutes. The ink was deposited on glassy carbon and spin-dried at room temperature, resulting in a loading of $20 \mu \mathrm{g}_{\mathrm{Pt}} \mathrm{cm}^{-2}$. All electrochemical measurements were carried out at $25^{\circ} \mathrm{C}$ in $0.1 \mathrm{M} \mathrm{HClO}_{4}$. The electrolyte was thoroughly purged with $\mathrm{N}_{2}$ for 30 minutes prior to each experiment, and bubbled through with $\mathrm{O}_{2}$ for at least 30 minutes for the ORR experiments. All chemicals used were analytical grade and solutions were prepared with deionized water (Millipore, 18.2 $\mathrm{M} \Omega \mathrm{cm}$ ). 


\section{Fuel cell testing}

The electrodes were prepared by spray-coating catalyst ink to the gas diffusion membrane (Johnson Matthey ELE0022). The catalyst ink was prepared by ultrasonicating the measured amount of catalyst in 2-propanol solution (Sigma-Aldrich) and Nafion solution for 30 minutes. The catalyst loading was determined by weighing the gas diffusion

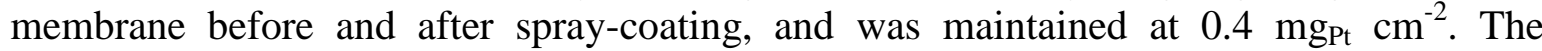
membrane electrode assembly (MEA) was prepared by hot-pressing anode and cathode (Johnson Mathhey ELE0162, $0.4 \mathrm{mg}_{\mathrm{Pt}} \mathrm{cm}^{-2}$ ) electrodes on either side of a Nafion 212 membrane at $130^{\circ} \mathrm{C}$ and 400 psi for 3 minutes. The effective electrode area was $5.29 \mathrm{~cm}^{2}$. Fuel cell measurements were carried out using a Scribner Associates 890e test station. The cell temperature was set at $80^{\circ} \mathrm{C}$, and the anode and cathode were fed with humidified (98\% relative humidity) $\mathrm{H}_{2}$ and $\mathrm{O}_{2}$, at stoichiometry 2.0 and 6.0, respectively. Prior to measurements, the MEA was activated by maintaining the cell current density in the sequence of $50 \mathrm{~mA} \mathrm{~cm}^{-2}, 100 \mathrm{~mA} \mathrm{~cm}^{-2}, 300 \mathrm{~mA} \mathrm{~cm}^{-2}, 500 \mathrm{~mA} \mathrm{~cm}^{-2}$, and $700 \mathrm{~mA} \mathrm{~cm}^{-2}$ for 30 minutes each.

\section{Results and Discussions}

\section{$\underline{\text { 3D interconnected pore structure of PTI-GO monolith }}$}

The 3D hybrid PTI-GO monolithic aerogels (Figure 3a) were prepared via a freeze casting method together with freeze-drying of PTI-GO solution with changing the initial solution concentrations (Figure 2), and can be further thermal treated to tailor the BET surface area and electrical conductivity. The mixed GO and PTI nanosheets disperse readily in water to form a stable dark brown colloidal dispersion due to the electrostatic repulsion between particles (50). The subsequent directional freeze casting of the suspension forms an anisotropic network structure (Figure 3b-c), where the top view shows the interconnected structure with sheet-like GO bridged by long fiber-shaped PTI particles, while the side view displays a directional long channel structure extending over hundreds of micrometers, along the ice growing direction where the ice expels the nanosheets, leading to the accumulation of nanosheets in the space between ice crystals (52). The representative EDX map shows uniform dispersion of $\mathrm{C}, \mathrm{N}, \mathrm{Br}$ and $\mathrm{O}$ among the whole interconnected network before thermal reduction. The final densities of the network range between $4-7 \mathrm{mg} \cdot \mathrm{cm}^{-3}$ depending on the concentration of the starting solutions. 

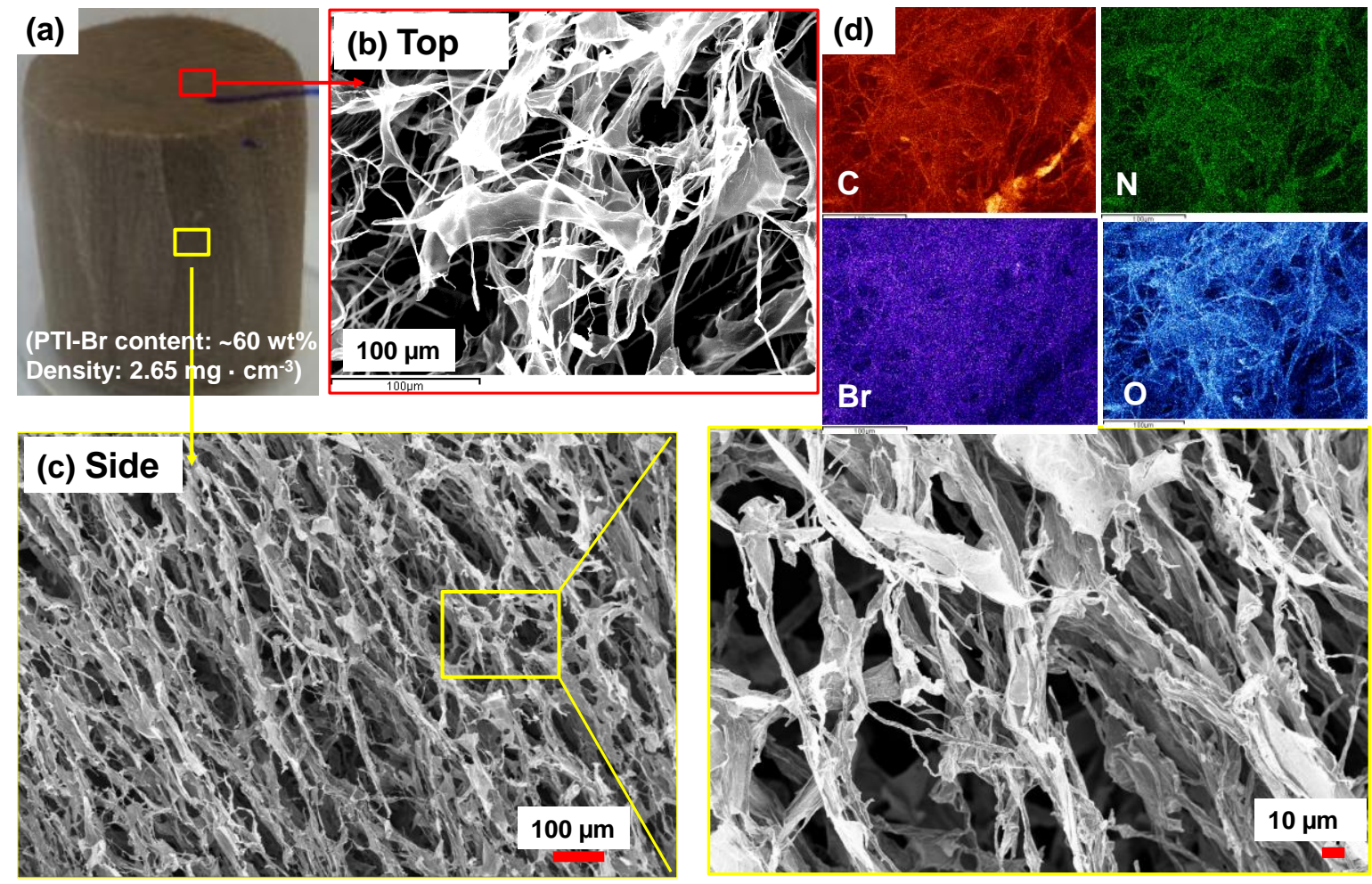

Figure 3. (a) Optical photograph of as-prepared PTI-GO monolith. (b) Top and side view images of PTI-GO monolith by SEM. (c) Typical EDX elemental mapping images of elements $\mathrm{C}, \mathrm{N}, \mathrm{Br}$ and $\mathrm{O}$.

\section{Characterization of Pt nanoparticles supported on PTI-rGO hybrid aerogels}

Figure 4a shows a typical TEM image of Pt nanoparticles on the surface of the PTI-rGO composite. The individual Pt particles range from 4 to $8 \mathrm{~nm}$ in size, with an average size of $4.9 \mathrm{~nm}$ (Figure 4b). A TEM image of Pt supported on rGO aerogel is shown in Figure 4c, showing a smaller particle size distribution ranging from 2 to $5 \mathrm{~nm}$, with an average size of $3.3 \mathrm{~nm}$. 


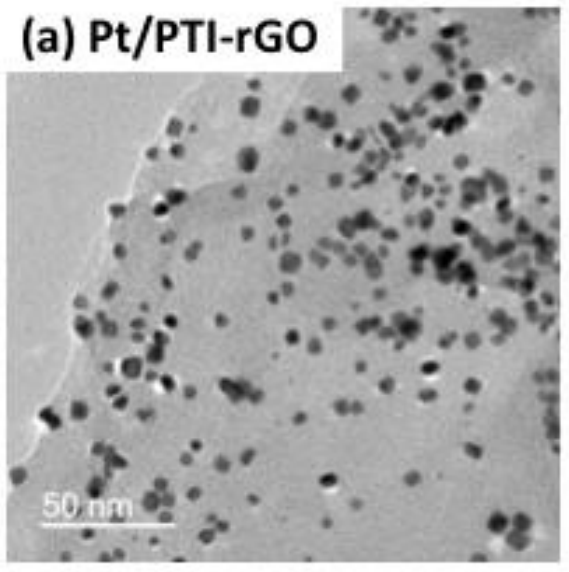

(b)
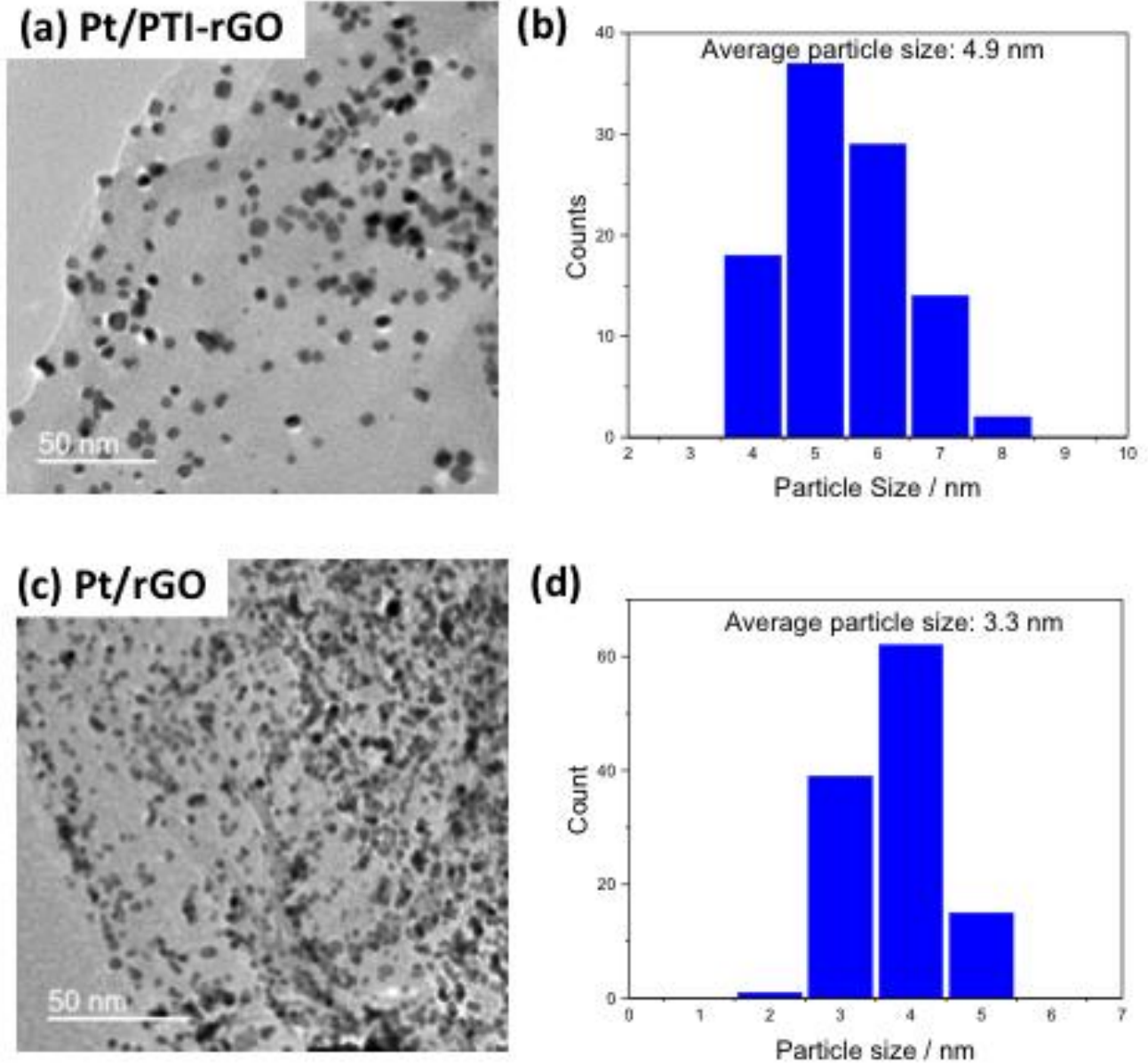

Figure 4. (a) TEM image of Pt nanoparticles supported on PTI-rGO hybrid aerogel. (b) Histogram showing the size distribution of Pt nanoparticles on PTI-rGO hybrid aerogel. (c) TEM image of Pt nanoparticles supported on rGO aerogel. (d) Histogram showing the size distribution of $\mathrm{Pt}$ nanoparticles on rGO aerogel.

The materials were tested on the rotating disk electrode (RDE) for ORR. The results, as shown in Figure 5, show that Pt supported on PTI-rGO hybrid aerogels exhibits enhanced ORR activity at $0.9 \mathrm{~V}$ with up to 10 -fold higher current density for $\mathrm{Pt} / \mathrm{PTI}_{3}-\mathrm{rGO}_{6.5}$ compared to Pt on bulk PTI. Pt/PTI $-\mathrm{rGO}_{6.5}$ also displays higher current density at the overpotential region $(0.90 \mathrm{~V})$, even though $\mathrm{Pt} / \mathrm{rGO}$ has smaller particle size, indicating that the combination of PTI and rGO improves the overall performance. The limiting current density of $\mathrm{Pt} / \mathrm{PTI}_{3}-\mathrm{rGO}_{6.5}$ is still lower than that of commercial $\mathrm{Pt} / \mathrm{C}$ but the results are encouraging, considering the high durability of the support material (27). However, increasing the amount of PTI, specifically for the $\mathrm{Pt} / \mathrm{PTI}_{1}-\mathrm{rGO}_{1}$ composite, decreases the performance. The incorporation of rGO is thought to enhance the conductivity of PTI, whereas PTI may act as a co-catalyst along with Pt. The nitrogen content on the PTI nanosheets may activate the neighbouring carbon atoms and accelerate the formation of $\mathrm{OH}$ species on the surface, thus promoting the removal adsorbed intermediate poisoning species, which in the case of ORR is hydrogen peroxide. However, the presence of too much PTI degrades the electrical conductivity of the support. 

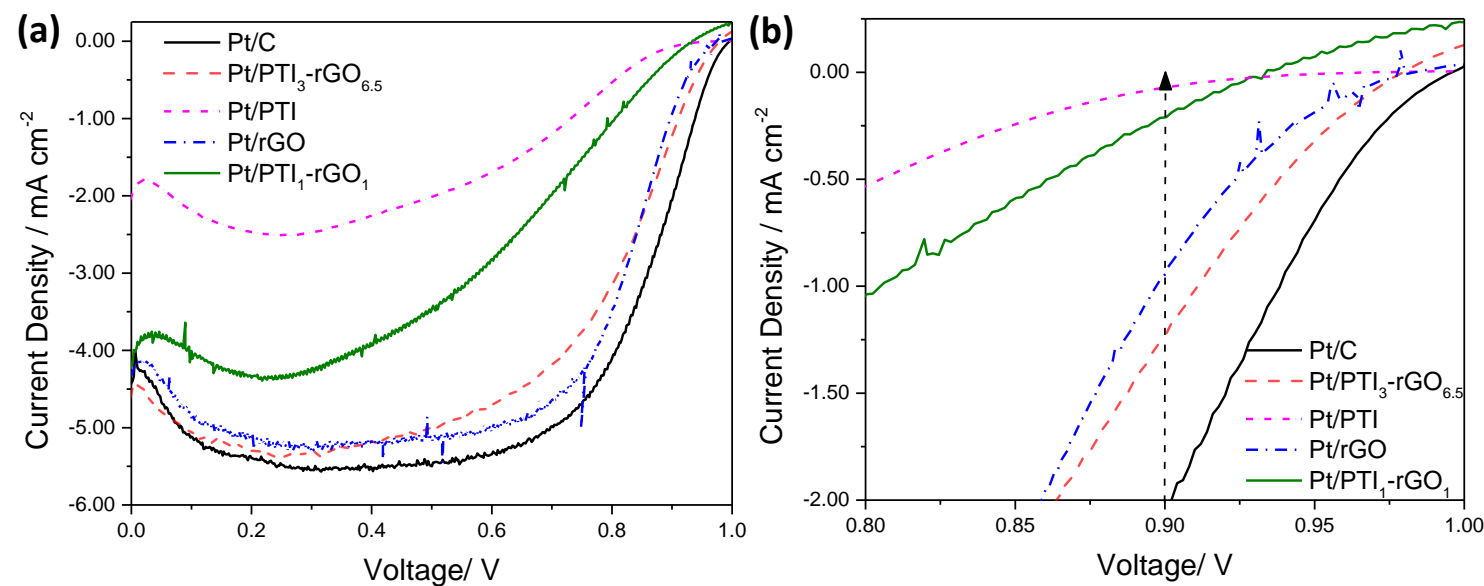

Figure 5. (a) Linear sweep voltammetry curves off ORR on Pt supported on aerogels in comparison to commercial Pt/C (Alfa Aesar), at $1600 \mathrm{rpm}$ in oxygen saturated $0.1 \mathrm{M}$ $\mathrm{HClO}_{4}$. (b) Enlargement of the overpotential region. Arrow indicates the current at $0.90 \mathrm{~V}$.

\section{Fuel cell testing}

Given the promising results on the RDE, the hybrid aerogel supported Pt catalysts were also tested in a PEM fuel cell device, as both cathode and anode catalyst supports. Figure 6 represents the polarization curves of $\mathrm{Pt} / \mathrm{PTI}_{3}-\mathrm{rGO}_{6.5}, \mathrm{Pt} / \mathrm{PTI}_{1}-\mathrm{rGO}_{1}$, and $\mathrm{Pt} / \mathrm{rGO}$ as the cathode catalyst, in comparison to a commercial Pt/C electrode (Johnson Matthey). As expected, the performance of $\mathrm{Pt} / \mathrm{PTI}_{3}-\mathrm{rGO}_{6.5}$ is better than $\mathrm{Pt} / \mathrm{PTI}_{1}-\mathrm{rGO}_{1}$ and $\mathrm{Pt} / \mathrm{rGO}$, corresponding to the results found on the RDE. However, all Pt supported on 3D aerogel materials are still significantly poorer than commercial $\mathrm{Pt} / \mathrm{C}$, with open circuit voltages $(\mathrm{OCVs}$ ) at least $130 \mathrm{mV}$ lower. Note that the performance of $\mathrm{Pt} / \mathrm{rGO}$ is lower than that reported in the literature for in-situ PEM fuel cells (53), meaning that there is still scope for improvement in terms of aerogel pore size, ink formulation and electrode fabrication. $\mathrm{Pt}$ supported on bulk PTI is not shown, as the conductivity and surface area are too low to work in fuel cells. 


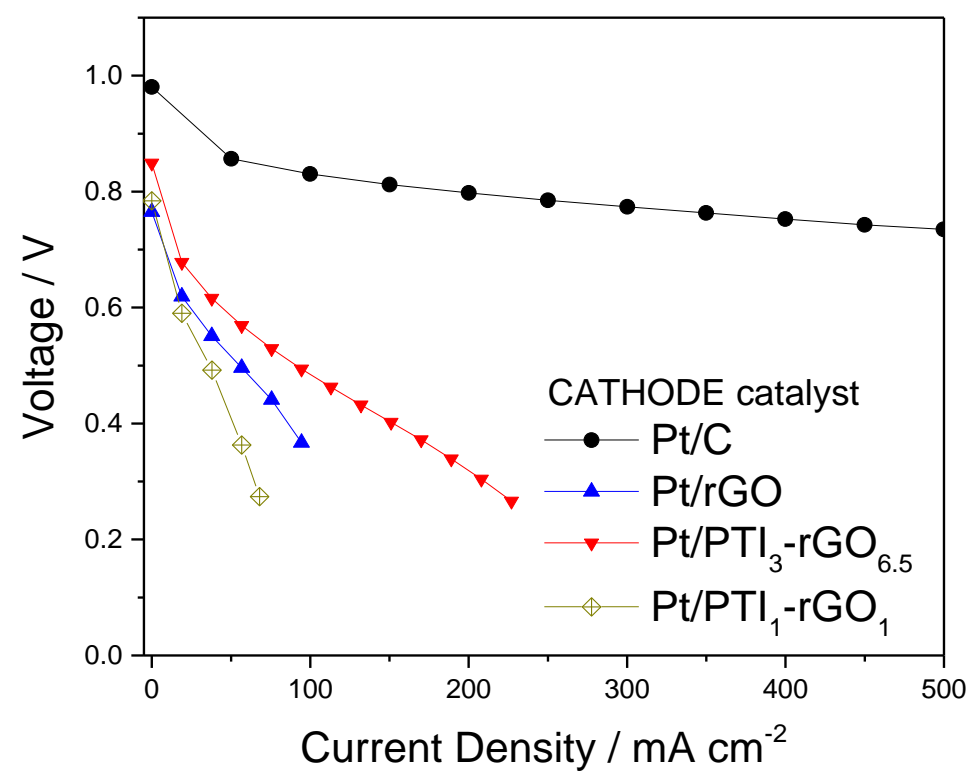

Figure 6. Polarization curves rGO aerogel, PTI-rGO aerogels and conventional carbon as cathode catalyst supports for Pt electrocatalysts. Pt loadings: $0.4 \mathrm{mg}_{\mathrm{Pt}} \mathrm{cm}^{-2}$. Conditions: $\mathrm{H}_{2} / \mathrm{O}_{2}$ fuel cell at $80^{\circ} \mathrm{C}$.

The polarization curves of the aerogel materials used as an anode catalyst support is shown in Figure 7. The performance of Pt supported aerogels follow the same trends as the cathode, with $\mathrm{Pt} / \mathrm{PTI}_{3}-\mathrm{rGO}_{6.5}$ showing the best performance, followed by $\mathrm{Pt} / \mathrm{rGO}$ and finally, $\mathrm{Pt} / \mathrm{PTI}_{1}-\mathrm{rGO}_{1}$. The OCVs of all supported catalysts, including commercial $\mathrm{Pt} / \mathrm{C}$, are around the same region (ca. $0.90-1.00 \mathrm{~V}$ ); however, all aerogel supported catalysts display smaller voltages as the current density is increased. Remarkably, bulk PTI supported catalyst has better performance than the hybrid aerogel supported catalysts. Despite the low surface area and electronic conductivity, the performance of Pt/PTI is similar to commercial Pt/C at low current densities, with voltage drop only beginning at $200 \mathrm{~mA} \mathrm{~cm}^{-2}$. Considering the high electrochemical durability of the PTI material in fuel cell environments (26), it could potentially replace conventional carbon support as a durable catalyst support in fuel cell anodes, which often suffer from durability issue resulting from normal fuel cell operations such as voltage reversal. In addition, the overall performance is better than that found for the cathode, which may imply that the PTI material has intrinsic catalytic activity for the hydrogen oxidation reaction (HOR). However, this reaction is very fast, and therefore, the electronic conductivity and surface area have less of an impact on the catalytic activity. The addition of graphene may improve the conductivity, but also lower the mass transport access due to the layered morphology of graphene, and therefore the cell is not able to support high voltages at high current densities for PTI-rGO hybrid materials. On the other hand, for the ORR, the catalytic activity is greatly reduced by the low conductivity and surface area, and the activity is improved only when a conductive substrate has been added. 


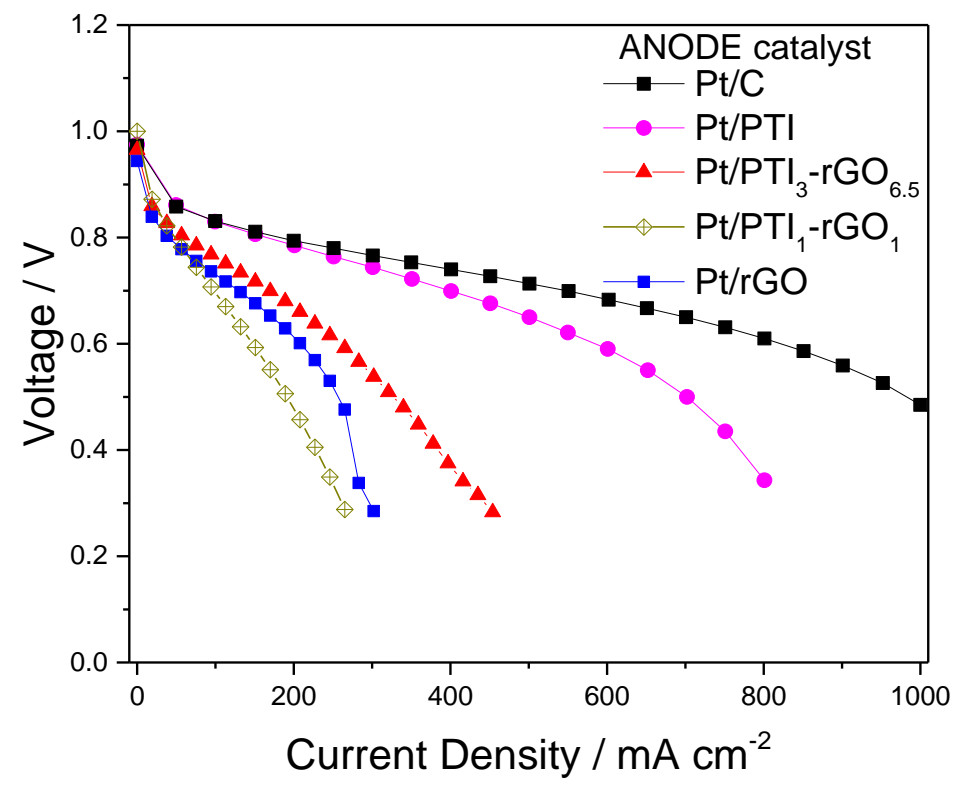

Figure 7. Polarization curves of PTI, rGO aerogel, PTI-rGO aerogels and conventional carbon as anode catalyst supports for Pt electrocatalysts. Pt loadings: $0.4 \mathrm{mg}_{\mathrm{Pt}} \mathrm{cm}^{-2}$. Conditions: $\mathrm{H}_{2} /$ air fuel cell at $80^{\circ} \mathrm{C}$.

\section{Conclusions}

Three-dimensional hybrid aerogels composed of exfoliated PTI and rGO have been successfully prepared. The materials were used as catalyst support for $\mathrm{Pt}$ and then investigated for its applications in PEM fuel cells. Ex-situ results on the RDE shows that the cathode catalytic activity of Pt/rGO-PTI hybrid is significantly improved in comparison to Pt/PTI or Pt/rGO, indicating that the combination of both PTI and rGO is beneficial to the catalytic activity. The same trend was observed in a PEM fuel cell device; however, the overall performance is still lower than commercial Pt/C. Further improvement in the performance can be achieved by optimizing the aerogel structure and pore size, as well as catalyst layer composition. On the other hand, Pt/PTI as anode catalyst has similar performance as commercial $\mathrm{Pt} / \mathrm{C}$, especially at low current densities. The results show the potential of the PTI material as a durable catalyst support for fuel cell anodes.

\section{Acknowledgments}

This project has received funding from the European Union's Horizon 2020 research and innovation programme under grant agreement No. 696656 - GrapheneCore1 and from the EPSRC EP/L017091/1. C.M. acknowledges the award of a Royal Society University Research Fellowship by the UK Royal Society.

\section{References}

1. J. Spendelow and J. Marcinkoski, Fuel Cell Technologies Office (2013). 
2. R. Borup, J. Meyers, B. Pivovar, Y. S. Kim, R. Mukundan, N. Garland, D. Myers, M. Wilson, F. Garzon, D. Wood, P. Zelenay, K. More, K. Stroh, T. Zawodzinski, J. Boncella, J. E. McGrath, M. Inaba, K. Miyatake, M. Hori, K. Ota, Z. Ogumi, S. Miyata, A. Nishikata, Z. Siroma, Y. Uchimoto, K. Yasuda, K.-i. Kimijima and N. Iwashita, Chem. Rev., 107, 3904 (2007).

3. Y. Shao, G. Yin, Z. Wang and Y. Gao, J. Power Sources, 167, 235 (2007).

4. P. J. Ferreira, G. J. la O', Y. Shao-Horn, D. Morgan, R. Makharia, S. Kocha and H. A. Gasteiger, J. Electrochem. Soc., 152, A2256 (2005).

5. J. C. Meier, C. Galeano, I. Katsounaros, A. A. Topalov, A. Kostka, F. Schüth and K. J. J. Mayrhofer, ACS Cat., 2, 832 (2012).

6. E. Antolini, Appl. Cat.al., B, 88, 1 (2009).

7. E. Antolini, Appl. Cat.al., B, 123-124, 52 (2012).

8. R. B. Kaner, J. Kouvetakis, C. E. Warble, M. L. Sattler and N. Bartlett, Mater. Res. Bull., 22, 399 (1987).

9. O. Stephan, P. M. Ajayan, C. Colliex, P. Redlich, J. M. Lambert, P. Bernier and P. Lefin, Science, 266, 1683 (1994).

10. W. Cermignani, T. E. Paulson, C. Onneby and C. G. Pantano, Carbon, 33, 367 (1995).

11. S. Wang, T. Cochell and A. Manthiram, Phys. Chem. Chem. Phys., 14, 13910 (2012).

12. S. Yang, L. Zhi, K. Tang, X. Feng, J. Maier and K. Müllen, Adv. Func. Mat., 22, 3634 (2012).

13. Z. Yang, Z. Yao, G. Li, G. Fang, H. Nie, Z. Liu, X. Zhou, X. a. Chen and S. Huang, ACS Nano, 6, 205 (2012).

14. Y. J. Lee and L. R. Radovic, Carbon, 41, 1987 (2003).

15. Z. W. Liu, F. Peng, H.-J. Wang, H. Yu, W.-X. Zheng and J. Yang, Angew. Chem. Int. Ed., 50, 3257 (2011).

16. Z. Liu, F. Peng, H. Wang, H. Yu, W. Zheng and X. Wei, J. Nat. Gas Chem., 21, 257 (2012).

17. R. Chetty, S. Kundu, W. Xia, M. Bron, W. Schuhmann, V. Chirila, W. Brandl, T. Reinecke and M. Muhler, Electrochim. Acta, 54, 4208 (2009).

18. S. Kundu, T. C. Nagaiah, W. Xia, Y. Wang, S. V. Dommele, J. H. Bitter, M. Santa, G. Grundmeier, M. Bron, W. Schuhmann and M. Muhler, J. Phys. Chem. C, 113, 14302 (2009).

19. Z. Lei, L. An, L. Dang, M. Zhao, J. Shi, S. Bai and Y. Cao, Microporous Mesoporous Mater., 119, 30 (2009).

20. J. Ozaki, T. Anahara, N. Kimura and A. Oya, Carbon, 44, 3358 (2006).

21. G. Wu, D. Li, C. Dai, D. Wang and N. Li, Langmuir, 24, 3566 (2008).

22. S. Pylypenko, A. Borisevich, K. L. More, A. R. Corpuz, T. Holme, A. A. Dameron, T. S. Olson, H. N. Dinh, T. Gennett and R. O'Hayre, Energy Environ. Sci., 6, 2957 (2013).

23. Y. Zhou, K. Neyerlin, T. S. Olson, S. Pylypenko, J. Bult, H. N. Dinh, T. Gennett, Z. Shao and R. O'Hayre, Energy Environ. Sci., 3, 1437 (2010).

24. T. Holme, Y. Zhou, R. Pasquarelli and R. O'Hayre, Phys. Chem. Chem. Phys., 12, 9461 (2010).

25. S. Ye, A. K. Vijh and L. H. Dao, J. Electrochem. Soc., 144, 90 (1997).

26. N. Mansor, A. B. Jorge, F. Corà, C. Gibbs, R. Jervis, P. F. McMillan, X. Wang and D. J. L. Brett, J. Phys. Chem. C, 118, 6831 (2014). 
27. N. Mansor, A. Belen Jorge, F. Corà, C. Gibbs, R. Jervis, P. F. McMillan, X. Wang and D. J. L. Brett, ECS Trans., 58, 1767 (2013).

28. M. Kim, S. Hwang and J.-S. Yu, J. Mater. Chem., 17, 1656 (2007).

29. A. Schwarzer, T. Saplinova and E. Kroke, Coord. Chem. Rev., 257, 2032 (2013).

30. M. J. Bojdys, J.-O. Müller, M. Antonietti and A. Thomas, Chem. Eur. J., 14, 8177 (2008).

31. E. Wirnhier, M. Döblinger, D. Gunzelmann, J. Senker, B. V. Lotsch and W. Schnick, Chem. Eur. J., 17, 3213 (2011).

32. X. Wang, K. Maeda, A. Thomas, K. Takanabe, G. Xin, J. M. Carlsson, K. Domen and M. Antonietti, Nat Mater, 8, 76 (2009).

33. D. Guo, R. Shibuya, C. Akiba, S. Saji, T. Kondo and J. Nakamura, Science, 351, 361 (2016).

34. A. B. Jorge, D. J. Martin, M. T. S. Dhanoa, A. S. Rahman, N. Makwana, J. Tang, A. Sella, F. Corà, S. Firth, J. A. Darr and P. F. McMillan, J. Phys. Chem. C, 117, 7178 (2013).

35. S. W. Kohl, L. Weiner, L. Schwartsburd, L. Konstantinovski, L. J. W. Shimon, Y. Ben-David, M. A. Iron and D. Milstein, Science, 324, 74 (2009).

36. Y. Wang, X. Wang and M. Antonietti, Angew. Chem. Int. Ed., 51, 68 (2012).

37. Y. Wang, Y. Di, M. Antonietti, H. Li, X. Chen and X. Wang, Chem. Mater., 22, 5119 (2010).

38. A. Thomas, A. Fischer, F. Goettmann, M. Antonietti, J.-O. Muller, R. Schlogl and J. M. Carlsson, J. Mater. Chem., 18, 4893 (2008).

39. Y. Zheng, Y. Jiao, J. Chen, J. Liu, J. Liang, A. Du, W. Zhang, Z. Zhu, S. C. Smith, M. Jaroniec, G. Q. Lu and S. Z. Qiao, J. Am. Chem. Soc., 133, 20116 (2011).

40. S. Yang, X. Feng, X. Wang and K. Müllen, Angew. Chem. Int. Ed., 50, 5339 (2011).

41. J. Liang, Y. Zheng, J. Chen, J. Liu, D. Hulicova-Jurcakova, M. Jaroniec and S. Z. Qiao, Angew. Chem. Int. Ed., 51, 3892 (2012).

42. C. Song and S. Kim, J. Electrochem. Soc., 162, F1181 (2015).

43.C. Z. Li, Z. B. Wang, X. L. Sui, L. M. Zhang and D. M. Gu, Carbon, 93, 105 (2015).

44. C. Hu, Q. Han, F. Zhao, Z. Yuan, N. Chen and L. Qu, Science China Mater., 58, 21 (2015).

45. A. Du, S. Sanvito, Z. Li, D. Wang, Y. Jiao, T. Liao, Q. Sun, Y. H. Ng, Z. Zhu, R. Amal and S. C. Smith, J. Am. Chem. Soc., 134, 4393 (2012).

46. K. Qiu and Z. X. Guo, J. Mater. Chem. A, 2, 3209 (2014).

47. Y. Sun, C. Li, Y. Xu, H. Bai, Z. Yao and G. Shi, Chem. Commun., 46, 4740 (2010).

48. W. Zhang, H. Huang, F. Li, K. Deng and X. Wang, J. Mater. Chem. A, 2, 19084 (2014).

49. Z. Li, R. Lin, Z. Liu, D. Li, H. Wang and Q. Li, Electrochim. Acta, 191, 606 (2016).

50. H. Huang, S. Yang, R. Vajtai, X. Wang and P. M. Ajayan, Adv. Mat., 26, 5160 (2014).

51. J. Jia, C.-M. Kan, X. Lin, X. Shen and J.-K. Kim, Carbon, 77, 244 (2014).

52. C. Ferraro, E. Garcia-Tunon, V. G. Rocha, S. Barg, F. M. Dolores, A.-A. T. E. Gomez, G. Sernicola, F. Giuliani and E. Saiz, Adv. Func. Mat., 26, 1636 (2016).

53. A. B. Jorge Sobrido, I. Dedigama, N. Mansor, R. Jervis, T. S. Miller, F. Corà, P. Shearing, C. Gibbs, P. F. McMillan and D. J. Brett, ECS Trans., 64, 13 (2015). 